AARP INTERNATIONAL THE JOURNAL

VOLUME 11 - 2018 EDITION

AATR

Real Possibilities

\title{
From the CEO: Preparing for an Aging World
}

By Jo Ann Jenkins 
From the CEO

\title{
Preparing for an Aging World
}

\author{
By Jo Ann Jenkins
}

W

hen we think of the big issues facing our world today - climate change is one example - a lot of the energy around the subject is consumed by ongoing debates as to whether the "thing" in question even exists, or about how it's defined, or on how various people believe it will (or won't) play out in the real world. But global aging is different: There are no world's aging population "deniers," or even skeptics. Look around, you won't find anyone who says, "Nope, I'm not buying it."

In a world where consensus is increasingly rare, there is sweeping agreement on a simple but powerful truth: the world is getting older - fast and just about everywhere. But far too often, we only see the challenges of aging and not the opportunities it also offers.

On every continent, leaders speak of being inundated by the effects of aging and its consequences. Who will pay for their pensions? Who will pay their medical bills? Who will care for them? There is no doubt that longer lives create challenges, and we wrestle with those questions every day.

But there is a bigger conversation to be had - focused not just on the historic burdens but on the potential historic benefits of living longer. What if instead of seeing just dependent retirees, we saw a new type of experienced, accomplished work force? What if instead of seeing expensive costs, we saw an exploding consumer market that could grow our economies? What if instead of seeing a growing pool of older people, we saw rich, intergenerational communities with new and different strengths?

The time has come to create a new mindset around aging - a new way of thinking about possible solutions to help us age better. The way people are aging is changing, but many of our attitudes and stereotypes about aging are not. We need to challenge those old stereotypes and attitudes and spark new solutions so more people can choose how they want to live as they age.

At AARP, we're igniting a worldwide effort to do just that - to Disrupt Aging. We want to change the conversation about what it means to grow older and change the way we think about aging and how we live throughout our lives, not just during our later years. It's more about how we live than about how long we live. That's what Disrupt Aging is all about.

We believe there is tremendous value in sharing information among nations, regions, communities and organizations. All of our international efforts are based on the premise that we can learn a lot from the experiences of other countries, and they can learn from our experiences as well. As such, AARP continues to develop and maintain strategic partnerships. We collaborate with others on international conferences, events and policy discussions to highlight and promote best practices. We work with organizations such as the World Economic Forum (which we joined in 2016), the Organization for Economic Cooperation and Development (OECD), the United Nations, national governments, and US Department of State. We also promote community building among civil society organizations serving older populations around the world.

In 2017, we introduced Disrupt Aging to the World Economic Forum in Davos, and this year we look forward to expanding that discussion. My book, Disrupt Aging: A Bold New Path to Living Your Best Life at Every Age, has been translated into Chinese with more international translations under consideration. And we engaged the 6,000 aging professionals (representing more than 70 countries) attending the International Association of Gerontology and Geriatrics World Congress in San Francisco in discussing their important role in disrupting aging.

Also in 2017, we decided to see how well prepared some of the world's key nations are for the challenges and opportunities their societies face as they age. ${ }^{1}$ We looked at the profound challenges their societies and economies face as the number of people aged 
60 and over in their populations more than doubles over the next generation. We released the AARP Aging Readiness and Competitiveness Report - or as we call it, the ARC Report - at the OECD Forum in Paris in May.

While these countries face formidable challenges as a result of their aging populations - especially those related to housing, mobility, isolation, finance, and healthcare - they are also coming up with innovative solutions to address many of these issues. I encourage you to review the research and the innovations at AARPinternational.org/arc

Because of the far-sighted vision of AARP's founder, Dr. Ethel Percy Andrus, AARP has been involved internationally almost from its start in 1958. This year, as we celebrate our 60th anniversary we continue to be everyday innovators in aging, changing the

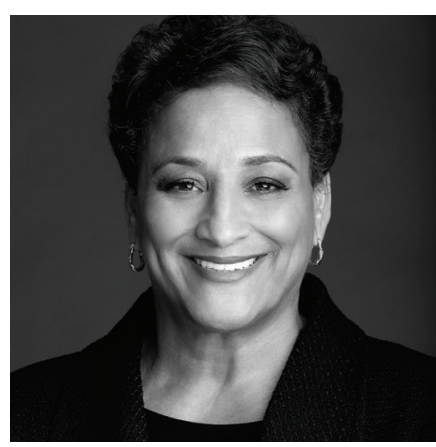

Jo Ann Jenkins CEO, AARP conversation and sparking new solutions so more people throughout the world can choose how they want to live as they age.

We are refining and expanding our global thought leadership. AARP will lead conversations at the United Nations, the German Marshall Fund, the OECD, the World Health Organization, and the World Economic Forum. I will also make my first visit to Asia as CEO, with planned visits to China, Japan, Korea, and Taiwan.

We also will expand the ARC research to include an additional set of countries that represent smaller economies around the world. And we will join with HelpAge International to launch Global AgeWatch Insights 2018, a research advocacy tool focusing on the health and care needs of older people in low and middle-income countries, particularly as it relates to their access to universal health coverage.

All of these efforts are designed to provide decision makers and civil society advocates around the world with a deeper analysis of aging issues as we all prepare to face the opportunities and challenges of an aging world.

${ }^{1}$ AARP Aging Readiness and Competitiveness (ARC) Report, AARP and FP Analytics, June 2017. The Report examines the preparedness levels of 12 nations

— Brazil, Canada, China, Germany, Israel, Japan, Korea, Mexico, South Africa, Turkey, the United Kingdom, and the United States. 
AARP International engages global stakeholders to spark solutions that strengthen communities, protect the vulnerable and enable people around the world to pursue their goals and dreams. Working with governments, civil society and the private sector, we are focused on enhancing the quality of life for people as they age. We serve as the global voice for AARP, a social change organization with a membership of more than 37 million.

THE JOURNAL ONLINE

aarpinternational.org/journal

AARP INTERNATIONAL ONLINE

aarpinternational.org

FACEBOOK

facebook.com/aarpintl

TWITTER

@aarpintl

CONTACT

AARP International

601 E Street, NW

Washington, DC 20049

United States

T +1 2024342398

E international@aarp.org

AARP International: The Journal is a publication of AARP. The views expressed herein do not necessarily represent policies of AARP and should not be construed as endorsements. The mention of a product or service herein is solely for information to our readers and may not be used for any commercial purpose. AARP, which was established in 1958, is a nonprofit, nonpartisan organization with tens of millions of members ages 50 and older. State offices are located in all 50 states, the District of Columbia, Puerto Rico, and the Virgin Islands.

January 2018

()2018, AARP

Reprinting with permission only. 